\title{
Biopsied Jaw Lesions in Kuwait: A Six-Year Retrospective Analysis
}

\author{
Mohammad A. Ali \\ Department of Diagnostic Sciences, Faculty of Dentistry, Kuwait University, Jabriya, Kuwait
}

\begin{abstract}
Key Words
Jaw lesions · Odontogenic cyst • Odontogenic tumor •

Keratocystic odontogenic tumor $\cdot$ Kuwait
\end{abstract}

\begin{abstract}
Objectives: The aim of this study was to determine the relative frequency of jaw lesions in Kuwait. Materials and Methods: Biopsy records and microscopic sections of all jaw biopsies seen in the Department of Histopathology at Amiri Hospital, Kuwait, during the period January 2004 to December 2009 were reviewed. The biopsies were divided into three major groups: developmental/inflammatory/reactive lesions (group 1), cystic lesions (group 2), and tumors and tumor-like lesions (group 3). Groups 2 and 3 were subdivided into odontogenic and nonodontogenic. Results: Three hundred and eighty-five cases were reviewed. Of the 385 cases, 115 (29.9\%) were in group 1, $178(46.2 \%)$ in group 2, and 92 (23.9\%) in group 3. Overall, radicular cysts $(n=95 ; 24.7 \%)$ were the most common biopsied jaw lesions, followed by chronic apical periodontitis ( $n=59 ; 15.3 \%$ ), dentigerous cysts ( $n=51$; $13.2 \%)$, and keratocystic odontogenic tumors $(n=30 ; 7.8 \%)$. In group 1, chronic apical periodontitis was the most frequent lesion ( $n=59 ; 51.3 \%$ ). In group 2 , odontogenic cysts $(n=166 ; 93.3 \%)$ were more frequent than nonodontogenic cysts $(n=12 ; 6.7 \%)$, and radicular cysts $(n=95 ; 53.4 \%)$ were the most frequent lesions in this group. Odontogenic tumors $(n=61 ; 66.3 \%)$ were more frequent than nonodontogenic tumors $(n=31 ; 33.7 \%)$ in group 3. Keratocystic odontogenic
\end{abstract}

tumors ( $n=30 ; 32.6 \%$ ) were the most frequent type of lesion in this group, followed by ameloblastoma ( $n=17 ; 18.5 \%)$. Only 3 malignant lesions were found in this study. Conclusions: Cystic and inflammatory lesions of the jaw are more common than tumors and tumor-like lesions of the jaw in Kuwait. The majority of inflammatory lesions that occurred in the jaw were related to periapical inflammation. Most cystic and tumorous jaw lesions were odontogenic in origin. Locally aggressive odontogenic tumors were relatively more common than nonaggressive ones. Malignant jaw tumors were relatively rare.

Copyright $\odot 2011$ S. Karger AG, Basel

\section{Introduction}

The jaw can be affected by a wide spectrum of lesions, ranging from inflammatory processes to malignant neoplasms $[1,2]$. Jaw lesions can be very aggressive; they can cause pain, paresthesia, swelling, drainage, tooth loss, root resorption, facial deformity, and other serious consequences [3].

There are several studies from around the world on the relative frequency of jaw lesions, including studies from other Arab countries [1,4-7], but there have been no studies on the relative frequency of jaw lesions in Kuwait. The aim of this study was to determine the relative frequency of jaw lesions seen at Amiri Hospital, Kuwait City, Kuwait, compared to previous reports from other countries. 
Table 1. Frequency of developmental/inflammatory/reactive lesions (group 1) and their distribution according to location, gender, and age

\begin{tabular}{|c|c|c|c|c|c|c|c|}
\hline \multirow[t]{2}{*}{ Diagnosis } & \multicolumn{4}{|l|}{ Location } & \multicolumn{2}{|c|}{ Gender } & \multirow{2}{*}{$\begin{array}{l}\text { Mean age } \\
\pm \mathrm{SD} \text {, years }\end{array}$} \\
\hline & n (\%) & Man & $\operatorname{Max}$ & NS & male & female & \\
\hline Chronic apical periodontitis & $59(51.3)$ & 34 & 23 & 2 & 28 & 31 & $35.4 \pm 15.4$ \\
\hline Osteomyelitis & $12(10.4)$ & 10 & 2 & & 8 & 4 & $41.9 \pm 20.0$ \\
\hline Condylar hyperplasia & $9(7.8)$ & 9 & - & & 5 & 4 & $22.6 \pm 6.6$ \\
\hline Dental abscess & $6(5.2)$ & 4 & 2 & & 4 & 2 & $38.2 \pm 16.3$ \\
\hline Perio-endo defect & $4(3.5)$ & 3 & 1 & & 2 & 2 & $41.3 \pm 12.3$ \\
\hline Foreign body granuloma & $3(2.6)$ & 1 & 2 & & 2 & 1 & $39.3 \pm 10.8$ \\
\hline Exostosis & $3(2.6)$ & 2 & 1 & & 2 & 1 & $41.7 \pm 1.5$ \\
\hline Condensing osteitis & $3(2.6)$ & 3 & 0 & & 1 & 2 & $35.7 \pm 6.7$ \\
\hline Idiopathic osteosclerosis & $3(2.6)$ & 2 & 1 & & 1 & 2 & $43.7 \pm 19.1$ \\
\hline Oroantral fistula & $3(2.6)$ & - & 3 & & 2 & 1 & $32.0 \pm 4.4$ \\
\hline Bone marrow defect & $3(2.6)$ & 3 & 0 & & 2 & 1 & $34.7 \pm 0.6$ \\
\hline Others $^{1}$ & $7(6.1)$ & 6 & 1 & & 4 & 3 & \\
\hline Total & $115(100)$ & 77 & 36 & 2 & 61 & 54 & \\
\hline
\end{tabular}

Man = Mandible; Max = maxilla; NS = not specified.

${ }^{1}$ Traumatic bone cyst $(n=2)$, tuberculosis $(n=1)$, traumatic neuroma $(n=1)$, bisphosphonate-induced osteonecrosis $(n=1)$, actinomycosis $(n=1)$, mucormycosis $(n=1)$.

\section{Materials and Methods}

The oral biopsy records of the Department of Histopathology at Amiri Hospital, which is one of the five major referral government hospitals in Kuwait, were reviewed for all jaw biopsies seen from January 2004 to December 2009. Hematoxylin and eosin-stained sections were reevaluated by 2 pathologists (M.A. and J.M.). Biopsies were divided into three major groups: group 1: developmental/ inflammatory/reactive lesions of the jaw; group 2: cysts, and group 3: tumors and tumor-like lesions. Groups 2 and 3 were both subdivided into odontogenic and nonodontogenic lesions. Clinical data such as age, gender, and location of lesions were collected. Reexcised and recurrent lesions were excluded from the study. Data were recorded and analyzed using the Statistical Package for the Social Sciences for Windows 17.0 (SPSS Inc, Chicago, Ill., USA).

\section{Results}

A total of 1,280 oral biopsies were found, 37 of which were for reexcised and recurrent lesions. Of the remaining 1,243 primary oral biopsies, 385 (31.6\%) were found in the jaw. Of the 385 cases, 248 (64.4\%) occurred in the mandible and 127 (33.0\%) in the maxilla. Also, of the 385 cases, $202(52.5 \%)$ were found in men and $183(47.5 \%)$ in women. The mean age of patients was $32.9 \pm 15.2$ years (range 4-91 years). The group distributions were as follows: group 1115 (29.9\%), group 2178 (46.2\%) and group 392 (23.9\%) (fig. 1).

Jaw Lesions in Kuwait

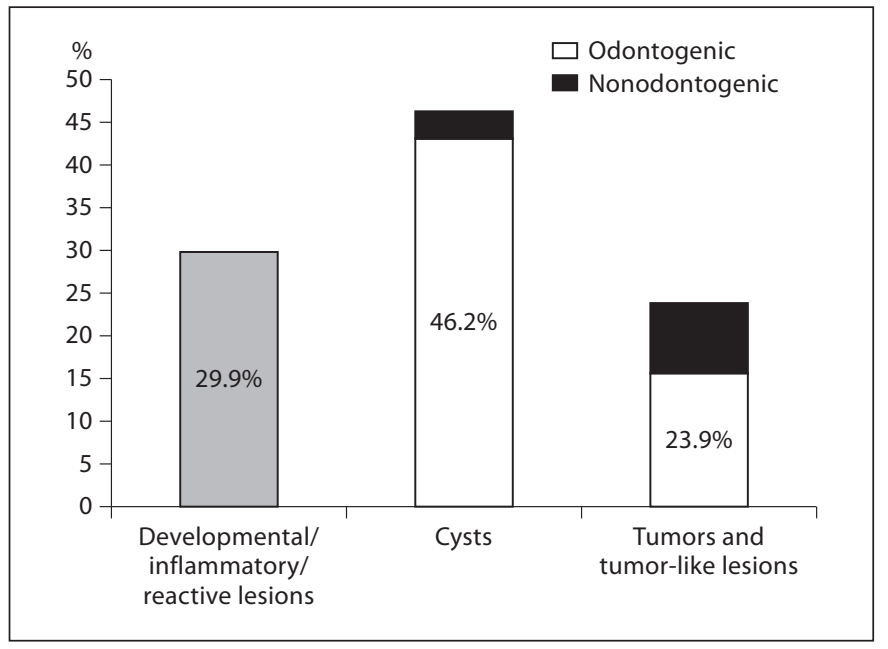

Fig. 1. Distribution of types of jaw biopsies $(n=385)$. 'Cysts' do not include keratocystic odontogenic tumor and calcifying cystic odontogenic tumors; 'tumors and tumor-like lesions' include keratocystic odontogenic tumors and calcifying cystic odontogenic tumors.

Overall, radicular cysts $(\mathrm{n}=95 ; 24.7 \%)$ were the most common biopsied jaw lesion, followed by chronic apical periodontitis $(\mathrm{n}=59 ; 15.3 \%)$, dentigerous cysts $(\mathrm{n}=51$; $13.2 \%)$, and keratocystic odontogenic tumors $(n=30$; $7.8 \%)$.

Med Princ Pract 2011;20:550-555 
Table 2. Frequency of cystic lesions (group 2) and their distribution according to location, gender, and age

\begin{tabular}{|c|c|c|c|c|c|c|c|}
\hline \multirow[t]{2}{*}{ Diagnosis } & \multicolumn{4}{|l|}{ Location } & \multicolumn{2}{|c|}{ Gender } & \multirow{2}{*}{$\begin{array}{l}\text { Mean age } \\
\pm S D, \text { years }\end{array}$} \\
\hline & $\mathrm{n}(\%)$ & Man & $\operatorname{Max}$ & NS & male & female & \\
\hline Odontogenic & $166(93.3)$ & & & & & & \\
\hline Radicular cyst & $95(53.4)$ & 45 & 44 & 6 & 55 & 40 & $32.8 \pm 14.3$ \\
\hline Dentigerous cyst & $51(28.7)$ & 43 & 8 & & 30 & 21 & $27.4 \pm 14.1$ \\
\hline Residual cyst & $8(4.5)$ & 6 & 2 & & 6 & 2 & $41.3 \pm 15.4$ \\
\hline Odontogenic cyst NS & $6(3.4)$ & 3 & 3 & & 3 & 3 & $44.3 \pm 9.3$ \\
\hline Glandular odontogenic cyst & $3(1.7)$ & 1 & 2 & & 3 & 0 & $32.7 \pm 11.1$ \\
\hline Orthokeratinized odontogenic cyst & $3(1.7)$ & 3 & 0 & & 2 & 1 & $34 \pm 14.9$ \\
\hline Nonodontogenic & $12(6.7)$ & & & & & & \\
\hline Nasopalatine duct cyst & $11(6.2)$ & 0 & 11 & & 6 & 5 & $38.7 \pm 20.1$ \\
\hline Surgical ciliated cyst & $1(0.6)$ & 0 & 1 & & 0 & 1 & 27 \\
\hline Total & $178(100)$ & 101 & 71 & 6 & 105 & 73 & \\
\hline
\end{tabular}

Man = Mandible; Max = maxilla; NS = not specified

Table 3. Frequency of tumor and tumor-like lesions (group 3) and their distribution according to location, gender, and age

\begin{tabular}{|c|c|c|c|c|c|c|c|}
\hline \multirow[t]{2}{*}{ Diagnosis } & \multicolumn{4}{|l|}{ Location } & \multicolumn{2}{|c|}{ Gender } & \multirow{2}{*}{$\begin{array}{l}\text { Mean age } \\
\pm S D, \text { years }\end{array}$} \\
\hline & $\mathrm{n}(\%)$ & Man & Max & NS & male & female & \\
\hline Odontogenic & $61(66.3)$ & & & & & & \\
\hline Keratocystic odontogenic tumor & $30(32.6)$ & 21 & 7 & 2 & 14 & 16 & $31.6 \pm 17.9$ \\
\hline Ameloblastoma & $17(18.5)$ & 15 & 2 & & 12 & 5 & $35.6 \pm 16.2$ \\
\hline Odontoma & $9(9.8)$ & 5 & 4 & & 2 & 7 & $19.7 \pm 8.2$ \\
\hline Calcifying cystic odontogenic tumor & $4(4.3)$ & 2 & 2 & & 0 & 4 & $21.5 \pm 11.0$ \\
\hline Calcifying epithelial odontogenic tumor & $1(1.1)$ & 1 & 0 & & 1 & 0 & 27 \\
\hline Nonodontogenic & $31(33.7)$ & & & & & & \\
\hline Central giant cell granuloma & $10(10.9)$ & 9 & 1 & & 2 & 8 & $26.7 \pm 19.5$ \\
\hline Ossifying fibroma & $4(4.3)$ & 4 & 0 & & 0 & 4 & $49.5 \pm 4.2$ \\
\hline Periapical cemento-osseous dysplasia & $3(3.3)$ & 3 & - & & 0 & 3 & $40.0 \pm 5.3$ \\
\hline Other benign tumors ${ }^{1}$ & $11(12.0)$ & 8 & 3 & & 1 & 10 & \\
\hline Malignant tumors ${ }^{2}$ & $3(3.3)$ & 2 & 1 & & 2 & 1 & \\
\hline Total & $92(23.9)$ & 70 & 20 & 2 & 36 & 56 & \\
\hline
\end{tabular}

Man = Mandible; Max = maxilla NS $=$ not specified

${ }^{1}$ Myofibroma $(n=2)$, osteoma $(n=2)$, eosinophilic granuloma $(n=2)$, hemangioma $(n=1)$, cherubism $(\mathrm{n}=1)$, brown tumor $(\mathrm{n}=1)$, osteoblastoma $(\mathrm{n}=1)$, chondromyxoid fibroma $(\mathrm{n}=1)$.

${ }^{2}$ Lymphoma $(n=1)$, myeloma $(n=1)$, metastatic breast carcinoma $(n=1)$.

Within group 1 (table 1), of the 115 cases, 59 (51.3\%) were of chronic apical periodontitis, 12 (10.4\%) osteomyelitis, and 9 (7.8\%) condylar hyperplasia. Within group 2 (table 2), of the 178 cystic lesions, 166 (93.3\%) were odontogenic. Within this group, $95(53.4 \%)$ cases were radicu- lar cysts, 51 (28.7\%) dentigerous cysts, and $11(6.2 \%)$ nasopalatine duct cysts. Within group 3 (table 3), of the 92 tumor and tumor-like lesions, $61(66.3 \%)$ were odontogenic. Within this group, $30(32.6 \%)$ cases were keratocystic odontogenic tumors, 17 (18.5\%) ameloblastomas, 
$10(10.9 \%)$ central giant cell granulomas, and $9(9.8 \%)$ odontomas. Of the 385 jaw lesions, only 3 (0.8\%) malignant nonodontogenic tumors were found.

\section{Discussion}

It was somewhat difficult to compare the findings of this study with those of other studies due to the dissimilarity of the methods used. Some of the studies were performed on a specific group of lesions such as odontogenic cysts or odontogenic tumors [1,4-7], while others were limited to a specific age group [8-10]. The percentage of jaw lesions of this study (31.0\%) is consistent with the 31.3\% in Greek children and adolescents [10].

The finding that cystic lesions were the most common of the three groups in the present study is consistent with the findings of Dhanuthai et al. [9] in Thai children and Utsumi et al. [11] in Japanese patients. Weir et al. [12], in their study, have also shown that reactive and cystic lesions were more common than neoplasms. The observation that radicular cysts were the most commonly biopsied lesions in our study is consistent with reports by Skiavounou et al. [10] in Greek children and adolescents and Satorres Nieto et al. [13] in Spanish patients. However, reports from the United Kingdom and Singapore demonstrated that chronic apical periodontitis was more common than radicular cysts $[14,15]$. A survey of pediatric oral lesions in Thailand by Dhanuthai et al. [9] reported that dentigerous cysts were more common than radicular cysts, but this finding was related to the high number of referred cases of dentigerous cysts, since the study was carried out at a major referral center. The present study showed in all three groups that the mandible was the most frequently affected site, similar to other studies in which the jaw lesions such as odontogenic cysts and odontogenic tumors were more frequently found in the mandible [5, 6, 16-19]. Lima et al. [8] found that jaw lesions were slightly more common in the maxilla than the mandible in Brazilian children, but this is probably due to the fact that lesions that have distinct predilection for the mandible, such as ameloblastoma and osteomyelitis, were not observed in this study, since they are uncommon in the pediatric population.

Chronic apical periodontitis was the most common lesion in the first group, which is consistent with the findings of several other studies $[10,12,14,15,20]$. However, it accounted for $4.7 \%$ of the total accepted oral biopsies, which is lower than $8.1-8.8 \%$ reported in other studies $[14,15]$. The difference might be due to the fact that chronic apical periodontitis lesions in Kuwait are often not submitted for microscopic examination, rather than to an actual lower occurrence of these lesions.

Cystic lesions in the present study comprised $14.3 \%$ of all accepted oral biopsies, which is within the range of $13.8-21.1 \%$ found in previous studies $[7,8,10,14,15]$, and the finding that the majority of cystic lesions were odontogenic cysts is consistent with the findings of many other researchers $[4,7,10,15]$. Odontogenic cysts in this study constituted $93.3 \%$ of the cystic lesions, which is slightly lower than the $95.6-97.2 \%$ reported in Sicilian and Greek subjects $[4,10]$. This difference might be due to the fact that in this study cases of odontogenic keratocysts and calcifying odontogenic cysts were not included within the cystic group, but were instead included in the group of tumors and tumor-like lesions. Due to their aggressive behavior, those lesions were reclassified as odontogenic tumors instead of cysts in the most recent World Health Organization (WHO) classification of odontogenic tumors $[4,7,21]$. The odontogenic keratocyst is now known as a keratocystic odontogenic tumor, and the calcifying odontogenic cyst is known as a calcifying cystic odontogenic tumor $[4,7,21]$. The most common nonodontogenic cyst in this study was the nasopalatine duct cyst, which is consistent with the findings of previous reports from Canada and the United Kingdom [7, 14].

The finding that the majority of the tumors and tumor-like lesions were odontogenic in origin is in agreement with the findings of most previous reports $[3,9]$. A report by Parkins et al. [22] from Ghana showed that nonodontogenic tumors were slightly more common, but this might be because nonaggressive odontogenic lesions such as odontomas were not detected in this study, since only symptomatic patients and patients who presented with facial swelling were included. Central giant cell granuloma was the most common nonodontogenic tumor in this study, which is consistent with the findings of previous reports from Libya and Brazil $[8,23]$.

Odontogenic tumors and tumor-like lesions comprised $4.9 \%$ of all accepted oral biopsies, which is within the range of $0.8-9.6 \%$ reported in previous studies $[7,8$, 10, 14-17]. Before the inclusion of keratocystic odontogenic tumors and calcifying cystic odontogenic tumors in the WHO list of odontogenic tumors, ameloblastoma and odontoma were the most common odontogenic tumors in most studies $[21,22]$. In this study, keratocystic odontogenic tumors were the most frequent odontogenic tumors, followed by ameloblastomas, which is consistent with the findings of recent reports $[16,23]$, whereas another study from China by Jing et al. [6] had shown that 
ameloblastomas (40.3\%) were slightly more common than keratocystic odontogenic tumors (35.8\%). This type of tumor constituted $49.2 \%$ of all odontogenic tumors in this study, which is higher than the $35.1 \%$ reported by ElGehani et al. [23] and 38.7\% reported by Luo and Li [16].

The finding that ameloblastomas were more common than odontomas is in agreement with the findings of most other studies carried out in Asian and African countries $[3,5,6,9,15-17,22,23]$, but contrasts with the findings of most North and South American studies, wherein odontomas were found to be more common than ameloblastomas [7, 24, 25]. A probable explanation is that the low incidence of odontomas could be related to ethnic or geographic variations $[5,7]$ or to the fact that most odontomas are nonaggressive and asymptomatic tumors, so that where radiographic examination is not performed routinely, most of them go undetected $[9,25]$. This might also be true for Kuwait, where many of the patients visit the dental clinic or undergo radiographic examination only for a dental emergency or when they have symptoms such as pain [26]. Other studies linked the low incidence of odontoma to the fact that odontomas are considered by some as hamartomatous lesions whose diagnosis can be suspected clinically, so even if they are surgically excised, the biopsy material is not usually sent for histopathologic examination [5, 6]. Fregnani et al. [27] from Brazil ascribed the difference in the prevalence of ameloblastoma and odontoma between different studies in different places mainly to data bias. They noticed that studies based on data from medical hospitals tend to have a higher incidence of ameloblastoma than those based on data from dental institutions, since most ameloblastoma cases are treated at hospitals because of their aggressive behavior, whereas most odontomas are treated in dental offices or schools [27]. The biopsies included in this study were received from dentists working in regional dental centers, but those dentists have easy access to the hospital's operating rooms for cases that need hospital facilities.

Benign tumors were far more common than malignant tumors in this study, which is in agreement with the findings of several previous studies $[3,5,10,22]$. No malignant odontogenic tumors were found in the present study. This observation confirms the findings of previous reports from other countries regarding the rarity of these lesions in the jaw $[5,7,17]$. The percentage of malignant odontogenic tumors in previous reports from other countries ranged from 0.3 to $3.4 \%$ of all odontogenic tumors $[5-7,17,24,25]$.

\section{Conclusions}

Cystic and inflammatory lesions of the jaw were more common than tumors and tumor-like lesions. The majority of inflammatory lesions that occurred in the jaw were related to periapical inflammation. Most cystic and tumorous lesions in the jaw were odontogenic in origin. Locally aggressive odontogenic tumors such as keratocystic odontogenic tumors and ameloblastomas were relatively more common than nonaggressive odontogenic tumors such as odontomas. Most benign tumors of the jaw were odontogenic in origin, while most malignant tumors were nonodontogenic in origin.

\section{Acknowledgments}

Special thanks to Dr. John P. Madda, Head of the Department of Histopathology, Amiri Hospital, for microscopic evaluation, and to Mrs. Lovely James, Department of Diagnostic Sciences, Faculty of Dentistry, Kuwait University for technical help.

\section{References}

$>1$ Bataineh AB, Rawashdeh MA, Al Qudah MA: The prevalence of inflammatory and developmental odontogenic cysts in a Jordanian population: a clinicopathologic study. Quintessence Int 2004;35:815-819.

$>2$ Regezi JA: Odontogenic cysts, odontogenic tumors, fibroosseous, and giant cell lesions of the jaws. Mod Pathol 2002;15:331-341.

$\checkmark 3$ Parkins GE, Armah G, Ampofo P: Tumours and tumour-like lesions of the lower face at Korle Bu Teaching Hospital, Ghana: an eight year study. World J Surg Oncol 2007;5:48. $\checkmark 4$ Tortorici S, Amodio E, Massenti MF, Buzzanca ML, Burruano F, Vitale F: Prevalence and distribution of odontogenic cysts in Sicily: 1986-2005. J Oral Sci 2008;50:15-18.

$\checkmark 5$ Okada H, Yamamoto H, Tilakaratne WM: Odontogenic tumors in Sri Lanka: analysis of 226 cases. J Oral Maxillofac Surg 2007;65: $875-882$.

6 Jing W, Xuan M, Lin Y, Wu L, Liu L, Zheng X, Tang W, Qiao J, Tian W: Odontogenic tumours: a retrospective study of 1642 cases in a Chinese population. Int J Oral Maxillofac Surg 2007;36:20-25.
Daley TD, Wysocki GP, Pringle GA: Relative incidence of odontogenic tumors and oral and jaw cysts in a Canadian population. Oral Surg Oral Med Oral Pathol 1994;77:276-280.

8 Lima Gda S, Fontes ST, de Araújo LM, Etges A, Tarquinio SB, Gomes AP: A survey of oral and maxillofacial biopsies in children: a singlecenter retrospective study of 20 years in Pelotas-Brazil. J Appl Oral Sci 2008;16:397-402.

9 Dhanuthai K, Banrai M, Limpanaputtajak S: A retrospective study of paediatric oral lesions from Thailand. Int J Paediatr Dent 2007; 17:248-253. 
10 Skiavounou A, Iakovou M, Kontos-Toutouzas J, Kanellopoulou A, Papanikolaou S: Intra-osseous lesions in Greek children and adolescents: a study based on biopsy material over a 26-year period. JClin Pediatr Dent 2005;30:153-156.

- 11 Utsumi N, Tajima Y, Oi T, Ohno J, Shikata H, Seki T, Miyamoto N, Kanada K, Yokoyama S, Shimada J: Report on clinico-pathological examinations in Meikai University. Meikai Daigaku Shigaku Zasshi 1990;19:383-398.

12 Weir JC, Davenport WD, Skinner RL: A diagnostic and epidemiologic survey of 15,783 oral lesions. J Am Dent Assoc 1987;115:439442.

13 Satorres Nieto M, Faura Solé M, Brescó Salinas M, Berini Aytés L, Gay Escoda C: Prevalence of biopsied oral lesions in a service of oral surgery. Med Oral 2001;6:296-305.

-14 Jones AV, Franklin CD: An analysis of oral and maxillofacial pathology found in adults over a 30-year period. J Oral Pathol Med 2006;35:392-401.

15 Tay AB: A 5-year survey of oral biopsies in an oral surgical unit in Singapore: 1993-1997. Ann Acad Med Singapore 1999;28:665-671.
16 Luo HY, Li TJ: Odontogenic tumors: a study of 1309 cases in a Chinese population. Oral Oncol 2009;45:607-611.

17 Ladeinde AL, Ajayi OF, Ogunlewe MO, Adeyemo WL, Arotiba GT, Bamgbose BO, Akinwande JA: Odontogenic tumors: a review of 319 cases in a Nigerian teaching hospital. Oral Surg Oral Med Oral Pathol Oral Radiol Endod 2005;99:191-195.

18 Avelar RL, Antunes AA, Carvalho RW, Bezerra PG, Oliveira Neto PJ, Andrade ES: Odontogenic cysts: a clinicopathological study of 507 cases. J Oral Sci 2009;51:581586.

19 De Vasconcelos Carvalho M, Iglesias DP, do Nascimento GJ, Sobral AP: Epidemiological study of 534 biopsies of oral mucosal lesions in elderly Brazilian patients. Gerodontology 2011;28:111-115.

20 Das S, Das AK: A review of pediatric oral biopsies from a surgical pathology service in a dental school. Pediatr Dent 1993;15:208-211.

21 Barnes L, Eveson JW, Richart P, Sidransky D: World Health Organization Classification of Tumors: Pathology and Genetics of Head and Neck Tumors. Lyon, IARC Press, 2005, p 306.
22 Parkins GE, Armah GA, Tettey Y: Orofacial tumours and tumour-like lesions in Ghana: a 6-year prospective study. $\mathrm{Br} J$ Oral Maxillofac Surg 2009;47:550-554.

23 El-Gehani R, Orafi M, Elarbi M, Subhashraj $\mathrm{K}$ : Benign tumours of orofacial region at Benghazi, Libya: a study of 405 cases. J Craniomaxillofac Surg 2009;37:370-375.

24 Ochsenius G, Ortega A, Godoy L, Peñafiel C, Escobar E: Odontogenic tumors in Chile: a study of 362 cases. J Oral Pathol Med 2002; $31: 415-420$.

25 Mosqueda-Taylor A, Ledesma-Montes C, Caballero-Sandoval S, Portilla-Robertson J, Ruíz-Godoy Rivera LM, Meneses-García A: Odontogenic tumors in Mexico: a collaborative retrospective study of 349 cases. Oral Surg Oral Med Oral Pathol Oral Radiol Endod 1997;84:672-675.

26 Al-Shammari KF, Al-Ansari JM, Al-Khabbaz AK, Honkala S: Barriers to seeking preventive dental care by Kuwaiti adults. Med Princ Pract 2007;16:413-419.

27 Fregnani ER, Fillipi RZ, Oliveira CR, Vargas PA, Almeida OP: Odontomas and ameloblastomas: variable prevalences around the world? Oral Oncol 2002;38:807-808. 